\title{
Association Between Metabolic Syndrome and Coronary Heart Disease in Patients on Hemodialysis
}

\author{
Mojgan Jalalzadeh ${ }^{1}$; Nouraddin Mousavinasab ${ }^{2}$; Mehrdad Soloki ${ }^{3}$; Reza Miri ${ }^{4}$; Mohammad \\ Hassan Ghadiani ${ }^{5,} ;$ Maryam Hadizadeh $^{6}$ \\ ${ }_{1}^{1}$ Department of Nephrology, Imam Hossein Hospital, Shahid Beheshti University of Medical Sciences, Tehran, IR Iran \\ ${ }^{2}$ Department of Biostatistics, Mazandaran University of Medical Sciences, Sari, IR Iran \\ ${ }^{3}$ Department of Pulmonary, Imam Hossein Hospital, Shahid Beheshti University of Medical Sciences, Tehran, IR Iran \\ 4 . \\ 5 Department of Cardiology, Imam Hossein Hospital, Shahid Beheshti University of Medical Sciences, Tehran, IR Ira \\ ${ }^{6}$ Department of Nephrology, Taleghani Hospital, Shahid Beheshti University of Medi
Vice Chancellor, Shahid Beheshti University of Medical Sciences, Tehran, IR Iran \\ *Corresponding author: Mohammad Hassan Ghadiani, Department of Nephrology, Taleghani Hospital, Shahid Beheshti University of Medical Sciences, Tehran, IR Iran. Tel: +98- \\ 2173430001, E-mail: j_mojgan@yahoo.com
}

Received: November 24, 2014; Revised: December 18, 2014; Accepted: January 13, 2015

\begin{abstract}
Background:The metabolic syndrome (MeS) is a common risk factor for coronary heart disease(CHD) in the general population.
Objectives: We examined the association between MeS and its risk in terms of CHD in patients on hemodialysis (HD).

Patients and Methods: This study was conducted on 300 patients on HD in six HD centers during March 2012. Patients were divided in two groups regarding presence of MeS. The rate of CHD were evaluated in each group and compared with each other.

Results: A total of 300 patients on HD, 173 males and 127 females with mean age of $61.7 \pm 14.2$, were enrolled in the study. Prevalence of MeS was 50.3\%; hypertension, 83.7\%; diabetes mellitus, 52\%; high triglyceride level, 34\%, low HDL cholesterol, 48.3\%; and abdominal obesity, 41.3\%. During the study, the CHD was more frequent in patients with $\mathrm{MeS}(27.8 \%)$ than was in those without MeS $(14.1 \%)(\mathrm{P}=0.004)$. In addition, stroke happened more frequently in the MeS group than in those without MeS (30.5\% vs. 17.4\%; $\mathrm{P}=0.008)$. The mean number of criteria for MeS was not significantly associated with mortality causes (CHD, 2.7 \pm 1.3 ; stroke, $2.8 \pm 0.9$; other causes, $2.9 \pm 1.3 \mathrm{P}=0.78$ ). However, hypertension (89.3\%) and diabetes mellitus (53.8\%) were associated with increased risk for mortality. In the group of MeS, CHD were not significantly associated with serum albumin, calcium, phosphate, blood urea nitrogen, creatinine, ferritin, C-reactive protein, and KT/V; but there was significant association with white blood cells count $(\mathrm{P}<0.0002)$.

Conclusions: These findings suggested MeS might be an important risk factor for CHD, but not for mortality due to CHD in patients on HD.
\end{abstract}

Keywords:Metabolic Syndrome; Hemodialysis; Coronary Heart Disease

\section{Background}

End-stage of renal disease (ESRD) has become a global public health challenge because of high prevalence of cardiovascular diseases (CVD) and premature death (1-6). Patients with ESRD have lower quality of life and shorter life expectancy compared with individuals of the same age in the general population (4). Studies have shown the association between metabolic syndrome (MeS) and increased risk of CVD (7). According to Adult Treatment Panel (ATP) III criteria (8), a person with three or more of the following criteria can clinically be considered as having MeS:1) abdominal obesity, waist circumference $>102$ $\mathrm{cm}$ in men and $>88 \mathrm{~cm}$ in women; 2 ) hypertriglyceridemia, triglyceride (TG) $\geq 150 \mathrm{mg} / \mathrm{dL}(1.695 \mathrm{mmol} / \mathrm{L}) ; 3$ ) low high-density lipoprotein (HDL) cholesterol $<40 \mathrm{mg} / \mathrm{dL}$ $(1.036 \mathrm{mmol} / \mathrm{L})$ in men and $<50 \mathrm{mg} / \mathrm{dL}(1.295 \mathrm{mmol} / \mathrm{L})$ in women; 4) high blood pressure ( $\geq 130 / 85 \mathrm{~mm} \mathrm{Hg}$ ); and 5) high fasting blood glucose (FBS) ( $\geq 110 \mathrm{mg} / \mathrm{dL}$ ). Identifying MeS has several advantages. Some researchers con- sider MeS a multiple risk factor for $\operatorname{CVD}(8,9)$ that its diagnosis will help treatment of important causes of CVD (10). However, there are those who disagree $(11,12)$. The role of $\mathrm{MeS}$ in the CHD in hemodialysis (HD) population has not been meticulously studied.

\section{Objectives}

The aim of this study was to see whether MeS caused adverse cardiovascular events (CVEs) in patients on HD.

\section{Patients and Methods}

This study was conducted during March 2012 in four HD centers affiliated with Shahid Beheshti University of Medical Sciences, Tehran, Iran, and in two HD centers affiliated with Zanjan University of Medical Sciences, Zanjan, Iran. We studied the presence of MeS in 300 patients on $\mathrm{HD}$ (173 males (57.7\%) and 127 females (42.3\%)), with the mean age

Copyright (C) 2015, Nephrology and Urology Research Center. This is an open-access article distributed under the terms of the Creative Commons Attribution-NonCommercial 4.0 International License (http://creativecommons.org/licenses/by-nc/4.0/) which permits copy and redistribute the material just in noncommercial usages, provided the original work is properly cited 
of $61.7 \pm 14.2$ years. In this study, MeS was defined according to ATP III criteria (8). The subjects were divided into two groups regarding presence of MeS criteria. All of the patients gave informed consent prior to data collection. Subjects were given a questionnaire to provide demographic data and medical histories. To assess CHD, we used the medical records of patients with chest pain and change of electrocardiogram (ECG), lab test, and wall motion abnormalities by ECG at cardiac care unit (CCU) admission. Moreover, serum predialysis blood urea nitrogen (BUN), creatinine $(\mathrm{Cr})$, fasting blood sugar (FBS), hemoglobin (Hb), albumin (Alb), cholesterol, TG, phosphor (P), and calcium (Ca) were measured. The two groups' measurements were compared. All examination and laboratory values were collected when the patients had reached their dry weight following the start of maintenance dialysis.

In addition, waist circumference was measured at $1 \mathrm{~cm}$ above the umbilicus at the end of HD session. The subjects who were administered antihypertensive medications were considered to have hypertension (HTN); the individuals who were administered antidiabetic medication were considered to have diabetes mellitus (DM). KT/V was used to evaluate the efficacy of dialysis. The level of blood pressure was recorded before and after HD. Duration of dialysis, age, and sex as well as the causes of ESRD were extracted from the patients' medical records and were used for the final analysis. The HD protocol for all patients was four hours of using hemophane membrane with an average blood flow rate of 300 to $350 \mathrm{~mL}$ per minute and with bicarbonate-basis dialysate. The median duration of dialysis was 48 months (range, 12 to 192 month). Subjects were excluded if they were assumed to have a life expectancy of less than six months or unwilling to sign informed consent.

\subsection{Statistical Analysis}

Normal distribution of data was assessed by the Kolmogorov-Smirnov test using Lilliefor's correction. The results were expressed as mean $\pm S D$, frequency (percentage) or median (range). Comparison of demographic and clinical characteristics between those subjects with and without MeS was performed by Student's t-test, Chi squared test and/or the Mann-Whitney U test. Differences in the proportions of categorical secondary outcome events between those with and without MeS were evaluated by the Chi squared test. Multiple logistic regressionderived odds ratios (OR) and 95\% CI were calculated to describe the associations between MeS and the variables. All data were analyzed by SPSS 18.0 (SPSS Inc, Chicago, Illinois, the United States). $\mathrm{P}<0.05$ were considered statistically significant.

\section{Results}

A total of 300 patients on HD including 173 males (57.7\%) and 127 females (42.3\%), with mean age of $61.7 \pm 14.2$ years, were enrolled. Out of the 300 subjects, 156 patients (52\%) had DM and 251 (83.7\%) had HTN. The participants' general characteristics are presented in Table 1 . The cause of ESRD in the subjects were as follows: HTN in 103 patients (34.3\%), diabetic nephropathy in 109 (36.3\%), chronic glomerulonephritis in 11 (3.6\%), polycystic kidney disease in 14 (4.7\%), urological problem in $9(3 \%)$, poisoning in $1(0.33 \%)$, autoimmune diseases in 3 (1\%), and idiopathic in 53 (17.7\%).

Table 1. Demographic, Metabolic, and Laboratory Features of Patients on Hemodialysis a,b

\begin{tabular}{|c|c|}
\hline Variable & Value \\
\hline Age, $y$ & $61.7 \pm 14.2$ \\
\hline \multicolumn{2}{|l|}{ Sex } \\
\hline Female & $127(42.3)$ \\
\hline Male & $173(57.7)$ \\
\hline Diabetes mellitus & $156(52)$ \\
\hline \multicolumn{2}{|l|}{ Metabolic features } \\
\hline Hypertension & $251(83.7)$ \\
\hline Systolic BP, mm Hg & $132.3 \pm 22.3$ \\
\hline Diastolic BP, mm Hg & $77.1 \pm 11.4$ \\
\hline Low HDLC & $145(48.3)$ \\
\hline Abnormal glucose metabolism & $140(46.7)$ \\
\hline Elevated triglycerides & $102(34)$ \\
\hline Obesity & $124(41.3)$ \\
\hline \multicolumn{2}{|l|}{ Serum laboratory features } \\
\hline HDLC, $\mathrm{mmol} / \mathrm{L}$ & $1.16 \pm 0.27$ \\
\hline $\mathrm{FBG}, \mathrm{mmol} / \mathrm{L}$ & $6.74 \pm 3.42$ \\
\hline Cholesterol, mmol/L & $4.08 \pm 1.09$ \\
\hline Triglyceride, mmol/L & $1.69 \pm 1.02$ \\
\hline Blood Urea Nitrogen, mmol/L & $27.38 \pm 16.06$ \\
\hline Creatinine, $\mu \mathrm{mol} / \mathrm{L}$ & $769.08 \pm 221.00$ \\
\hline Sodium, mmol/L & $138.8 \pm 3.5$ \\
\hline Potassium, mmol/L & $5.21 \pm 0.7$ \\
\hline Calcium, mmol/L & $2.26 \pm 0.18$ \\
\hline Phosphorus, mmol/L & $1.58 \pm 0.39$ \\
\hline Hemoglobin, mmol/L & $114 \pm 76$ \\
\hline Albumin, $\mathrm{mmol} / \mathrm{L}$ & $41 \pm 23$ \\
\hline Ferritin, mmol/L & $1386.00 \pm 1612.89$ \\
\hline CRP, nmol/dL & $190.48[0-1142.88]$ \\
\hline $\mathrm{KT} / \mathrm{V}$ & $1.21 \pm 0.25$ \\
\hline $\begin{array}{l}\text { Duration of treatment with } \\
\text { hemodialysis, mo }\end{array}$ & $48[12-192]$ \\
\hline WBC & $6.4 \times 10^{9} / \mathrm{L}\left(2.5 \times 10^{9} / \mathrm{L}-15.7 \times 10^{9} / \mathrm{L}\right)$ \\
\hline PLT & $178 \times 10^{9} / \mathrm{L}\left(67 \times 10^{9} / \mathrm{L}-623 \times 10^{9} / \mathrm{L}\right)$ \\
\hline iPTH, ng/L & $244.5[8-2000]$ \\
\hline $\mathrm{Fe}, \mu \mathrm{mol} / \mathrm{L}$ & $13.75[3.40-39.56]$ \\
\hline TIBC, $\mu \mathrm{mol} / \mathrm{L}$ & $51.10 \pm 10.95$ \\
\hline AST, $\mu$ kat $/ \mathbf{L}$ & $0.30[0.07-3.52]$ \\
\hline ALT, $\mu$ kat/L & $0.28[0.08-2.29]$ \\
\hline Serum Uric acid, $\mu \mathrm{mol} / \mathrm{L}$ & $416.40 \pm 88.63$ \\
\hline \multicolumn{2}{|c|}{$\begin{array}{l}\text { Data are presented as mean } \pm \text { SD or No. (\%), or median [range]. } \\
\text { b Abbreviations: ALT, alanine transferase; AST, aspartate transferase; BP, } \\
\text { blood pressure; CRP, C-reactive protein; FBG, fasting blood glucose; Fe, } \\
\text { iron; HDLC, high-density lipoprotein cholesterol; iPTH, immunoreactive } \\
\text { parathyroid hormone; PLT, platelet; TIBC, total iron binding capacity; } \\
\text { and WBC, white blood cell. }\end{array}$} \\
\hline
\end{tabular}


Prevalence of MeS was 50.3\% (151 patients). Characteristics of study participants with MeS are shown in Table 2. The most common element of MeS was HTN (135 patients (89.4\%)), followed by DM (117 patients (77.5\%), low HDL cholesterol (116 patients (76.8\%)), evidence of abdominal obesity (102 patients (67.5\%)), and elevated TG (85 patients (56.3\%)). Moreover, MeS was significantly associated with sex (Table 3 ). Its prevalence was $40.5 \%$ (70 patients) in males and $68.8 \%$ (81 patients) in females $(\mathrm{P}<0.0001)$. However, MeS was not significantly associated with patient's age.
Figure 1 displays the frequency of components of MeS in patients on HD according to sex. Patient's sex did not show significant association with abnormality in glucose metabolism $(\mathrm{P}=0.86)$, but prevalence of low HDL was significantly higher in females than in males (65.4\% vs. $35.8 \%$; $\mathrm{P}<0.001)$. In addition, MeS was not significantly associated with age and duration of HD and was not significantly associated with BUN, Cr, Ca, P, immunoreactive parathyroid hormone (iPTH), Alb, $\mathrm{Hb}$, iron, total iron binding capacity (TIBC), ferritin, C-reactive protein (CRP), and Kt/V.

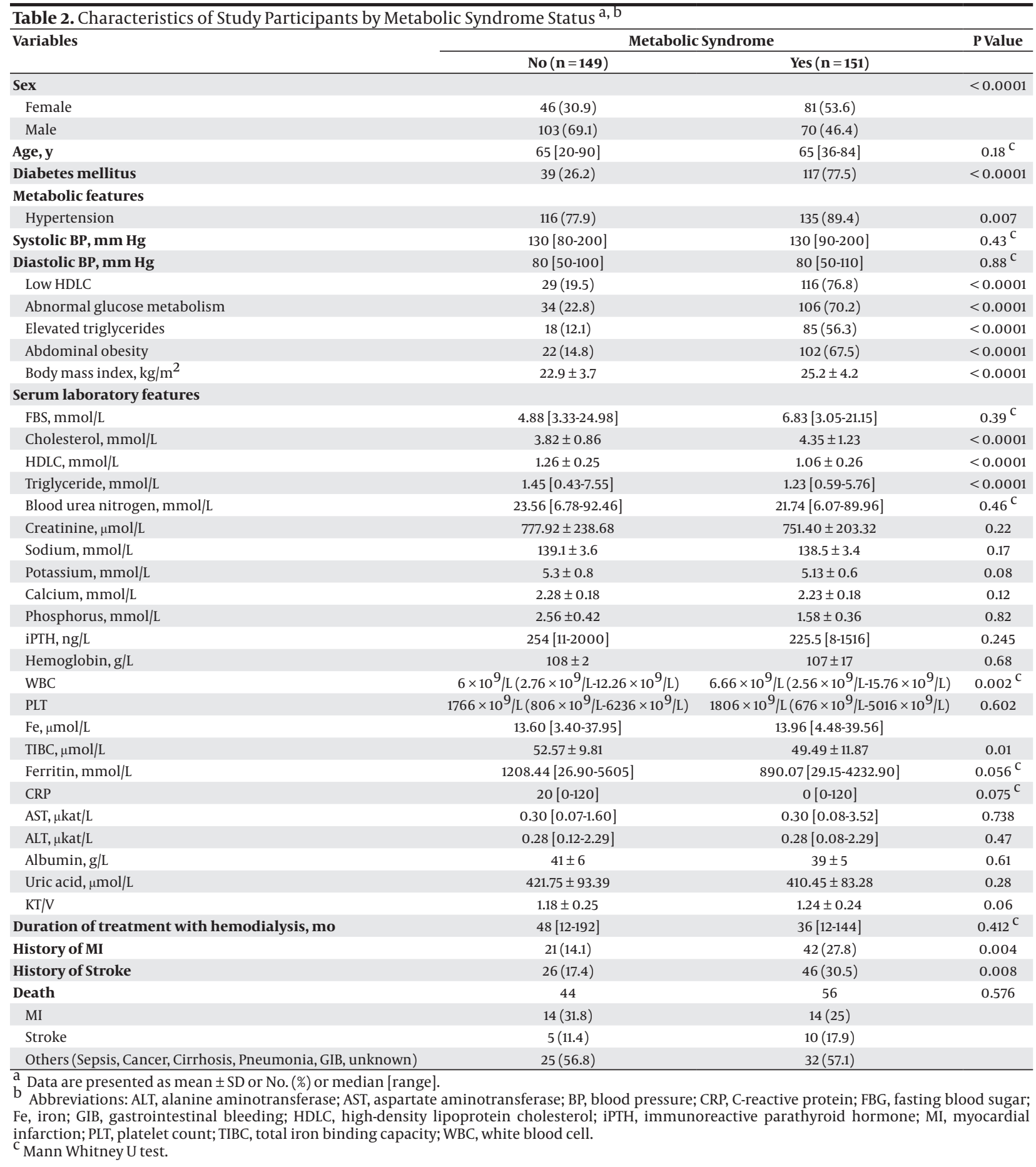


During the study, the CHD occurred more frequently in patients with MeS (42 patients $(27.8 \%)$ ) than in those without MeS (21 patients $(14.1 \%))(\mathrm{P}=0.004)$. The rate of death due to CHD was $28.6 \%$ (12 patients) in those with MeS and $23.8 \%$ (5 patients) in those without MeS, showing no significant differences (Table 2). In addition, stroke happened more frequently in the MeS group (46 patients $(30.5 \%)$ ) than in those without MeS (26 patients $(17.4 \%))(\mathrm{P}=0.008)$. The rate of death due to stroke was 28.3\% (13 patients) in the MeS group and 23.1\% (6 patients) in those without MeS, showing no significant differences (Table 2).

\begin{tabular}{|c|c|c|c|}
\hline Variables & Female $(n=127)$ & $\operatorname{Male}(n=173)$ & PValue \\
\hline Metabolic syndrome & $81(63.8)$ & $70(40.5)$ & $<0.0001$ \\
\hline Age, y & $62.4 \pm 13.5$ & $61.2 \pm 14.7$ & 0.48 \\
\hline Diabetes mellitus & $65(51.2)$ & $91(52.6)$ & 0.81 \\
\hline \multicolumn{4}{|l|}{ Metabolic features } \\
\hline Hypertension & $105(82.7)$ & $146(84.4)$ & 0.69 \\
\hline Systolic BP, mmHg & $130[80-200]$ & $130[90-200]$ & $0.19^{\mathrm{C}}$ \\
\hline Diastolic BP, mmHg & $80[50-100]$ & $80[50-110]$ & $0.71^{\mathrm{C}}$ \\
\hline Low HDLC & $83(65.4)$ & $62(35.8)$ & $<0.0001$ \\
\hline Elevated triglycerides & $56(44.1)$ & $47(27.2)$ & 0.002 \\
\hline Abnormal glucose metabolism & $60(47.2)$ & $80(46.2)$ & 0.86 \\
\hline Abdominal obesity & $78(61.4)$ & $46(26.6)$ & $<0.0001$ \\
\hline Body mass index, $\mathrm{kg} / \mathrm{m}^{2}$ & $24.2 \pm 4.6$ & $23.9 \pm 3.7$ & 0.67 \\
\hline \multicolumn{4}{|l|}{ Serum laboratory features } \\
\hline $\mathrm{FBS}, \mathrm{mmol} / \mathrm{L}$ & $5.44[3.05-21.15]$ & $5.38[3.39-24.98]$ & $0.39^{\mathrm{C}}$ \\
\hline Cholesterol, mmol/L & $4.41 \pm 1.13$ & $3.85 \pm 1.00$ & $<0.0001$ \\
\hline HDLC, $\mathrm{mmol} / \mathrm{L}$ & $1.21 \pm 0.33$ & $1.12 \pm 0.22$ & 0.003 \\
\hline Triglyceride, $\mathrm{mmol} / \mathrm{L}$ & $1.45[0.43-7.55]$ & $1.23[0.59-5.76]$ & $0.001^{\mathrm{C}}$ \\
\hline Blood urea nitrogen, $\mathrm{mmol} / \mathrm{L}$ & $23.56[6.78-92.46]$ & $21.74[6.07-89.96]$ & $0.46^{\mathrm{C}}$ \\
\hline Creatinine, $\mu \mathrm{mol} / \mathrm{L}$ & $7.7 .20 \pm 203.32$ & $804.44 \pm 221.00$ & $<0.0001$ \\
\hline Sodium, mmol/L & $138.80 \pm 3.5$ & $138.84 \pm 3.5$ & 0.93 \\
\hline Potassium, mmol/L & $5.13 \pm 0.7$ & $5.27 \pm 0.7$ & 0.11 \\
\hline Calcium, mmol/L & $2.28 \pm 0.18$ & $2.25 \pm 0.18$ & 0.28 \\
\hline Phosphorus, mmol/L & $1.55 \pm 0.29$ & $1.58 \pm 0.42$ & 0.19 \\
\hline iPTH, ng/L & 231 [8-1919] & 248 [11-2000] & 0.32 \\
\hline Hemoglobin, $\mathrm{g} / \mathrm{L}$ & $108 \pm 18$ & $107 \pm 18$ & 0.68 \\
\hline WBC & $6.4 \times 10^{9} / \mathrm{L}\left(2.7 \times 10^{9} / \mathrm{L}-14.8 \times 10^{9} / \mathrm{L}\right)$ & $6.4 \times 10^{9} / \mathrm{L}\left(2.5 \times 10^{9} / \mathrm{L}-15.7 \times 10^{9} / \mathrm{L}\right)$ & 0.934 \\
\hline PLT & $182 \times 10^{9} / \mathrm{L}\left(67 \times 10^{9} / \mathrm{L}-450 \times 10^{9} / \mathrm{L}\right)$ & $175 \times 10^{9} / \mathrm{L}\left(80 \times 10^{9} / \mathrm{L}-623 \times 10^{9} / \mathrm{L}\right)$ & 0.249 \\
\hline $\mathrm{Fe}, \mu \mathrm{mol} / \mathrm{L}$ & $13.96[4.48-39.56]$ & $13.43[3.40-33.29]$ & 0.99 \\
\hline $\mathrm{TIBC}, \mu \mathrm{mol} / \mathrm{L}$ & $49.83 \pm 10.81$ & $52.05 \pm 10.99$ & 0.08 \\
\hline Ferritin, $\mathrm{mmol} / \mathrm{L}$ & $1208.44[26.90-5605]$ & $890.07[29.15-4232.90]$ & $0.56^{\mathrm{C}}$ \\
\hline CRP & $0[0-120]$ & $20[0-120]$ & 0.296 \\
\hline AST, $\mu$ kat/L & $0.32[0.08-1.06]$ & $0.28[0.07-3.52]$ & 0.34 \\
\hline ALT, $\mu$ kat/L & $0.28[0.08-1.92]$ & $0.28[0.28-2.29]$ & 0.22 \\
\hline Albumin, $\mathrm{g} / \mathrm{L}$ & $41 \pm 6$ & $39 \pm 5$ & 0.14 \\
\hline Uric acid, $\mu \mathrm{mol} / \mathrm{L}$ & $404.50 \pm 71.38$ & $422.34 \pm 9$ & 0.06 \\
\hline $\mathrm{KT} / \mathrm{V}$ & $1.22 \pm 0.3$ & $1.21 \pm 0.3$ & 0.74 \\
\hline $\begin{array}{l}\text { Duration of treatment with } \\
\text { hemodialysis, mo }\end{array}$ & $48(12-144)$ & $39.6(12-192)$ & 0.423 \\
\hline History of MI & $26(20.5)$ & $37(21.4)$ & 0.84 \\
\hline History of Stroke & $35(27.6)$ & $37(21.4)$ & 0.216 \\
\hline Death, $n$ & 46 & 54 & 0.55 \\
\hline MI & $13(28.3)$ & $15(27.8)$ & \\
\hline Stroke & $5(10.9)$ & $10(18.5)$ & \\
\hline $\begin{array}{l}\text { Others (sepsis, cancer, cirrhosis, pneumo- } \\
\text { nia, GIB, unknown) }\end{array}$ & $28(60.9)$ & $29(53.7)$ & \\
\hline
\end{tabular}


Table 4 shows the rate of CVEs and causes of death in both groups. The mean number of criteria for MeS was significantly associated with the history of stroke (2.91 \pm 1.2 vs. 2.49 $\pm 1.3 ; \mathrm{P}=0.014)$, but it was not associated with the history of $\mathrm{CHD}(2.84 \pm 1.1$ vs. $2.5 \pm 1.3 ; \mathrm{P}=0.08)$. The mean number of criteria for MeS was not significantly associated with mortality causes (CHD, $2.7 \pm 1.3$; stroke, $2.8 \pm 0.9$; and other causes, $2.9 \pm 1.3 ; \mathrm{P}=0.78)$. In addition, among the MeS criteria, HTN (89.3\%, 25 patients) and DM (53.8\%, 15 patients) were associated with an increased risk of mortality (Tables 5 - 6).

The rate of HTN was $84.4 \%$ in males (146 patients) and 82.7\% in females (105 patients), while the rate of DM was $52.6 \%$ among males (91 patients) and 51.2\% among females
(65 patients). There was no significant difference between male and female subjects in CHD and death occurrence. Logistic regression showed that patients with MeS had history of HTN (OR, 5.3; 95\% CI, 2.67-10.52; and P < 0.001), history of $\mathrm{DM}(\mathrm{OR}, 2.9$; 95\% CI, 1.49-5.72;and $\mathrm{P}=0.002)$, higher body mass index (OR, 1.1; 95\% CI, 1.02-1.19; and $\mathrm{P}=0.018)$, and higher TG (OR, 1.01; 95\% CI, 1.008-1.02; and P < 0.001), and were mostly female (OR, 2.53; 95\% CI, 1.38-4.63; P = 0.003) (Table 7). In the MeS group, CHD were not significantly associated with serum Alb, Ca-P product, iPTH, Hb, platelet, iron, CRP, uric acid, BUN, Cr, and KT/V; nonetheless, there was significant association with white blood cell count ( $\mathrm{P}$ $=0.002)$ (Table 3$)$.

Table 4. The Rate of CardiovascularEvents and Causes of Death in the Both Groups of Study a,b

\begin{tabular}{|c|c|c|c|c|c|c|c|c|}
\hline \multirow[t]{2}{*}{ Variables } & \multicolumn{4}{|c|}{ With Metabolic syndrome } & \multicolumn{4}{|c|}{ Without Metabolic Syndrome } \\
\hline & Female $(\mathbf{n}=\mathbf{8 1})$ & Male $(\mathbf{n}=70)$ & OR & 95\% CI & Female $(n=46)$ & Male $(n=103)$ & OR & 95\% CI \\
\hline History of MI & $18(22.2)$ & $24(34.3)$ & 0.5 & $0.26-1.12$ & $8(17.4)$ & $13(12.6)$ & 1.45 & $0.5-3.8$ \\
\hline $\begin{array}{l}\text { History of } \\
\text { stroke }\end{array}$ & $26(32.1)$ & $20(28.6)$ & 1.18 & $0.5-2.3$ & $9(19.5)$ & $17(16.5)$ & 1.23 & $0.5-2.4$ \\
\hline \multicolumn{9}{|l|}{$\begin{array}{l}\text { Cause of } \\
\text { death }\end{array}$} \\
\hline No. & 35 & 21 & & & 11 & 33 & & \\
\hline MI & $9(25.7)$ & $5(23.8)$ & & & $4(36.3)$ & $10(30.3)$ & & \\
\hline CVA & $4(11.4)$ & $6(28.6)$ & & & $1(9.1)$ & $4(12.1)$ & & \\
\hline Others ${ }^{\mathrm{c}}$ & $22(62.9)$ & $10(47.6)$ & & & $6(54.5)$ & $19(57.6)$ & & \\
\hline
\end{tabular}

${ }^{\mathrm{a}}$ Data are presented as No. (\%).

b Abbreviations: OR, odds ratio; CVA, cardiovascular accident; GIB, gastrointestinal bleeding; and MI, myocardial infarction.

' Sepsis, Cancer, Cirrhosis, Pneumonia, gastrointestinal bleeding, and Unknown.

Table 5. Number of Metabolic Syndrome Criteria Among Them With Circulation Events a,b

\begin{tabular}{|c|c|c|c|c|c|c|c|}
\hline \multirow[t]{2}{*}{ Variables } & \multirow[t]{2}{*}{$\mathbf{n}$} & \multicolumn{6}{|c|}{ Metabolic Syndrome Criteria, No. } \\
\hline & & $\mathbf{0}$ & 1 & 2 & 3 & 4 & 5 \\
\hline History of MI & 63 & 0 & $10(15.9)$ & $11(17.5)$ & $25(39.7)$ & $13(20.6)$ & $4(6.3)$ \\
\hline $\begin{array}{l}\text { History of } \\
\text { stroke }\end{array}$ & 72 & 0 & $11(15.3)$ & $15(20.8)$ & $24(33.3)$ & $13(18.1)$ & $9(12.5)$ \\
\hline \multicolumn{8}{|c|}{ Cause of death } \\
\hline MI & 28 & 0 & $5(17.9)$ & $9(32.1)$ & $6(21.4)$ & $5(17.9)$ & $3(10.7)$ \\
\hline Stroke & 15 & 0 & $1(6.7)$ & $4(26.7)$ & $6(40)$ & $4(26.7)$ & 0 \\
\hline Others ${ }^{\mathrm{c}}$ & 57 & 0 & $8(14)$ & $17(29.8)$ & $11(19.3)$ & $14(24.6)$ & $7(12.3)$ \\
\hline
\end{tabular}

a Data are presented as No. or No.(\%).

b Abbreviations: CVA, cardiovascular accident; GIB, gastrointestinal bleeding; and MI, myocardial infarction.

c Sepsis, Cancer, Cirrhosis, Pneumonia, gastrointestinal bleeding, and Unknown.

Table 6. The Rate of Criteria for Metabolic Syndrome ${ }^{a, b}$

\begin{tabular}{|c|c|c|c|c|c|c|}
\hline Death due to & No. & HTN & DM & Abdominal & HDL & TG \\
\hline MI & 28 & $25(89.3)$ & $15(53.8)$ & $16(57.1)$ & $12(42.8)$ & $8(28.5)$ \\
\hline Stroke & 15 & $15(100)$ & $8(53.3)$ & $5(33.3)$ & $10(66.7)$ & $5(33.3)$ \\
\hline others $^{\mathrm{C}}$ & 57 & $52(91.2)$ & $39(68.4)$ & $28(49.1)$ & $28(49.1)$ & $19(33.3)$ \\
\hline
\end{tabular}

\footnotetext{
a Data are presented as No. or No.(\%).

b Abbreviations: DM, diabetes mellitus; HDL, high-density lipoprotein; HTN, hypertension; MI, myocardial infarction; and TG, triglyceride.

c Sepsis, Cancer, Cirrhosis, Pneumonia, gastrointestinal bleeding, Unknown.
} 
Jalalzadeh $\mathrm{M}$ et al.

\begin{tabular}{|c|c|c|c|c|c|c|}
\hline \multirow{2}{*}{$\begin{array}{l}\text { Variables } \\
\text { History of Hy- } \\
\text { pertension }\end{array}$} & \multirow{2}{*}{$\frac{\text { Beta }}{1.66}$} & \multirow{2}{*}{$\frac{\text { Standard Error }}{0.35}$} & \multirow{2}{*}{$\begin{array}{l}\text { PValue } \\
<0.001\end{array}$} & \multirow{2}{*}{$\begin{array}{c}\text { Odds Ratio } \\
5.3\end{array}$} & \multicolumn{2}{|c|}{ 95\% CI } \\
\hline & & & & & 2.67 & 10.52 \\
\hline $\begin{array}{l}\text { History of } \\
\text { Diabetes }\end{array}$ & 1.07 & 0.34 & 0.002 & 2.9 & 1.49 & 5.72 \\
\hline Gender & 0.92 & 0.31 & 0.003 & 2.53 & 1.38 & 4.63 \\
\hline BMI & 0.95 & 0.4 & 0.018 & 1.1 & 1.02 & 1.19 \\
\hline TG & 0.014 & 0.003 & $<0.001$ & 1.01 & 1.008 & 1.02 \\
\hline Age & 0.005 & 0.1 & 0.65 & 1.005 & 0.98 & 1.03 \\
\hline FBS & 0.005 & 0.003 & 0.12 & 1.005 & 0.99 & 1.01 \\
\hline
\end{tabular}

a Abbreviations: BMI, body mass index; FBS, fasting blood glucose; and TG, triglyceride.

Figure 1. Frequency of Metabolic Syndrome Components in Patients on Hemodialysis by Sex

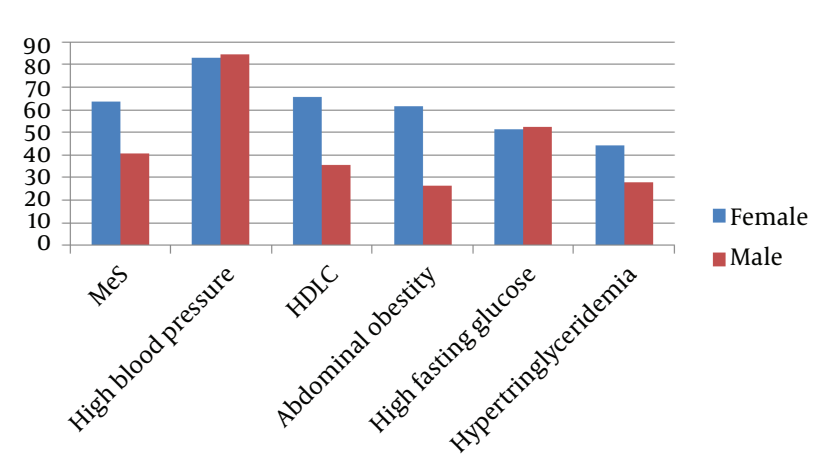

HDLC indicates high-density lipoprotein cholesterol.

\section{Discussion}

The CVD affects patients with ESRD and is the leading cause of death in patients on dialysis $(13,14)$. Increased risks of CVEs in patients on dialysis could be partially explained by traditional and nontraditional cardiovascular risk factors (15-19). Numerous studies have shown MeS to be a significant risk factor for CVD, mortality, and chronic kidney disease (CKD) in the general population $(15,17-20)$. $\mathrm{MeS}$ is a way of approaching traditional CVD risk factors. Secondary therapy can help prevent morbidity and mortality associated with CHD in the general population (17, 21). In addition, MeS has been shown to be an independent predictor of CVD mortality in patients with type 2 $\operatorname{DM}(22,23)$.

Because some usual risk factors associated with the general population have an inverse survival association in the maintenance of dialysis population (24), we decided to evaluate the correlation of the MeS with CHD in patients on HD. There are a few reports about the incidence of MeS among HD population $(14,25)$. The prevalence of MeS in stages 4 and 5 CKD population in the Australian population is reported to be less than $20 \%$ (26). Hamada et al. reported the metabolic syndrome incidence rate of
$62 \%$ in patients on $\mathrm{HD}$ (74.4\% in females, $52.7 \%$ in males) (25). Stolic et al. demonstrated that approximately $30 \%$ of patients on HD had MeS (27). In one of our earlier studies, the prevalence of MeS among patients on HD was $28.7 \%$ (39.1\% in females, $60.9 \%$ in males) (28).

In the present study, we studied a larger sample size. Moreover, the sample included patients on HD from two different geographical regions. The prevalence of MeS was $50.3 \%$, which might be due to larger sample size. Bakker et al. reported that the most common element of MeS was HTN, $85 \%$ of subjects had HTN while $46 \%$ had DM (29). In the present study, we obtained similar results $(89.4 \%$ had HTN; 77.5\%, DM).

MeS has important preventive implications for certain group of patients. CVD and all-cause mortality has been shown to increase in middle-aged Finnish men with MeS (17). Data from NHANES II (National Health and Nutrition Examination Survey) show that incidence rate of CHD, CVD, and total mortality were increased in the United States adult population with MeS (13). Our study showed that sex had an effect on the rate of MeS, but CHD and mortality due to CHD were not affected by sex (Table 3).

Johnson et al. have shown (30) that MeS happens in $30.5 \%$ of patients with stages 4 and 5 CKD. It is also associated with older age and a significant increase risk of future CVEs. However, our study showed that occurrence of $\mathrm{MeS}$ was not associated with age. In addition, age was also not associated with the occurrence of CHD and mortality due to CHD (Table 3). Data in patients with type $2 \mathrm{DM}$ are contradictory. Bonora et al. demonstrated that MeS was associated with a significant increase in CVD risk in patients with type2 DM (30). Yet another study showed that identification of MeS in patients with type $2 \mathrm{DM}$ did not improve CVD mortality $(22,23)$. In the present study, the incidence rate of MeS in patients with DM was 75\% (117 patients) and the incidence rate for CHD was 26.5\% (31 patients). Among the subjects without MeS, the rate of DM and CHD were 39\% (39 patients) 10.3\% (4 patients), respectively. Moreover, $\mathrm{CHD}$ occurred more frequently in patients with DM and MeS $(\mathrm{P}=0.035)$.

Another study demonstrated that treatments targeting hypercholesterolemia, hyperhomocysteinemia, ane- 
mia, and mineral metabolism bone disorder could not adequately explain the increase in cardiovascular risk among patients with CKD and MeS (31). In our study, CVEs were not significantly associated with serum Alb, Ca-P product, BUN, Cr, CRP, ferritin, and KT/V. In our study, MeS occurred in $50.3 \%$ of the subjects. The risk of future CHD and occurrence of stroke significantly increased in the MeS group in comparison with those without MeS. There was no significant difference between these two groups in terms of death rate due to CHD and stroke. Hypercholesterolemia, anemia, and bone mineral metabolism disorder had no role in development of CHD and stroke in patients with MeS in the HD population.

The mean number of criteria for MeS was significantly associated with the patients' history of stroke, but it was not associated with the patients' history of CHD. The mean number of criteria for MeS was not significantly associated with the cause of mortality. Sex had an effect on the rate of MeS in our study population, but it did not have an association with CHD occurrence in the MeS group. Moreover, MeS was not significantly associated with age. Future studies could help determine the prevalence of MeS in the ESRD population and the viability of MeS to predict CVD, CHD morbidity and mortality in ESRD patients.

The limitations of the present study were the prevalence rates of MeS in the general population and in the early stage of patients with CKD as they were unavailable for comparison. Being free of CHD was not documented as coronary angiography was not performed in all patients. The follow-up duration was not sufficient to assess cardiac mortality.

\section{Authors' Contributions}

Study concept and design: Mojgan Jalalzadeh, Mohammad Hassan Ghadiani, Reza Miri, and Mehrdad Soloki. Acquisition of data: Mojgan Jalalzadeh, Mohammad Hassan Ghadiani, Reza Miri, Mehrdad Soloki, and Maryam Hadizadeh. Analysis and interpretation of data: Nouraddin Mousavinasab and Mojgan Jalalzadeh. Drafting of the manuscript: Mojgan Jalalzadeh. Critical revision of the manuscript for important intellectual content: Mojgan Jalalzadeh and Nouraddin Mousavinasab. Statistical analysis: Nouraddin Mousavinasab.

\section{Funding/Support}

Shahid Beheshti University of Medical Sciences and Zanjan University of Medical Sciences provided practical support for the focus group and survey processes, including letters of endorsement, hospital contact information, and assistance with logistic arrangements for focus group sessions.

\section{References}

1. Meguid El Nahas A, Bello AK. Chronic kidney disease: the global challenge. Lancet. 2005;365(9456):331-40.

2. Coresh J, Astor BC, Greene T, Eknoyan G, Levey AS. Prevalence of chronic kidney disease and decreased kidney function in the adult US population: Third National Health and Nutrition Examination Survey. Am J Kidney Dis. 2003;41(1):1-12.

3. Chen J, Wildman RP, Gu D, Kusek JW, Spruill M, Reynolds K, et al. Prevalence of decreased kidney function in Chinese adults aged 35 to 74 years. Kidney Int. 2005;68(6):2837-45.

4. National Kidney F. K/DOQI clinical practice guidelines for chronic kidney disease: evaluation, classification, and stratification. Am J Kidney Dis. 2002;39(2 Suppl 1):S1-266.

5. Go AS, Chertow GM, Fan D, McCulloch CE, Hsu CY. Chronic kidney disease and the risks of death, cardiovascular events, and hospitalization. N Engl J Med.2004;351(13):1296-305.

6. Muntner P, He J, Hamm L, Loria C, Whelton PK. Renal insufficiency and subsequent death resulting from cardiovascular disease in the United States. J Am Soc Nephrol. 2002;13(3):745-53.

7. Segura J, Campo C, Roldan C, Christiansen H, Vigil L, Garcia-Robles R, et al. Hypertensive renal damage in metabolic syndrome is associated with glucose metabolism disturbances. J Am Soc Nephrol. 2004;15 Suppl 1:S37-42.

8. Grundy SM, Cleeman JI, Daniels SR, Donato KA, Eckel RH, Franklin BA, et al. Diagnosis and management of the metabolic syndrome: an American Heart Association/National Heart, Lung, and Blood Institute Scientific Statement. Circulation. 2005;112(17):2735-52.

9. Alberti KG, Zimmet P, Shaw J, I. D. F. Epidemiology Task Force Consensus Group . The metabolic syndrome--a new worldwide definition. Lancet. 2005;366(9491):1059-62.

10. Grundy SM. Metabolic syndrome: a multiplex cardiovascular risk factor. J Clin Endocrinol Metab. 2007;92(2):399-404.

11. Kahn R, Buse J, Ferrannini E, Stern M, American Diabetes A, European Association for the Study of D. The metabolic syndrome: time for a critical appraisal: joint statement from the American Diabetes Association and the European Association for the Study of Diabetes. Diabetes Care. 2005;28(9):2289-304.

12. Reaven GM. The metabolic syndrome: is this diagnosis necessary? Am J Clin Nutr. 2006;83(6):1237-47.

13. Malik S, Wong ND, Franklin SS, Kamath TV, L'Italien GJ, Pio JR, et al. Impact of the metabolic syndrome on mortality from coronary heart disease, cardiovascular disease, and all causes in United States adults. Circulation. 2004;110(10):1245-50.

14. Young DO, Lund RJ, Haynatzki G, Dunlay RW. Prevalence of the metabolic syndrome in an incident dialysis population. Hemodial Int. 2007;11(1):86-95.

15. Lakka HM, Laaksonen DE, Lakka TA, Niskanen LK, Kumpusalo E, Tuomilehto J, et al. The metabolic syndrome and total and cardiovascular disease mortality in middle-aged men. JAMA. 2002;288(21):2709-16.

16. Longenecker JC, Coresh J, Powe NR, Levey AS, Fink NE, Martin A, et al. Traditional cardiovascular disease risk factors in dialysis patients compared with the general population: the CHOICE Study. JAm Soc Nephrol. 2002;13(7):1918-27.

17. National Cholesterol Education Program Expert Panel on Detection E, Treatment of High Blood Cholesterol in A. Third Report of the National Cholesterol Education Program (NCEP) Expert Panel on Detection, Evaluation, and Treatment of High Blood Cholesterol in Adults (Adult Treatment Panel III) final report. Circulation. 2002;106(25):3143-421.

18. Isomaa B, Almgren P, Tuomi T, Forsen B, Lahti K, Nissen M, et al. Cardiovascular morbidity and mortality associated with the metabolic syndrome. Diabetes Care. 2001;24(4):683-9.

19. Onat A, Ceyhan K, Basar O, Erer B, Toprak S, Sansoy V. Metabolic syndrome: major impact on coronary risk in a population with low cholesterol levels--a prospective and cross-sectional evaluation. Atherosclerosis. 2002;165(2):285-92.

20. Ridker PM, Buring JE, Cook NR, Rifai N. C-reactive protein, the metabolic syndrome, and risk of incident cardiovascular events: an 8-year follow-up of 14719 initially healthy American women. Circulation. 2003;107(3):391-7.

21. Expert Panel on Detection E, Treatment of High Blood Cholesterol in A. Executive Summary of The Third Report of The National Cholesterol Education Program (NCEP) Expert Panel on Detection, Evaluation, And Treatment of High Blood Cholesterol In Adults (Adult Treatment Panel III). JAMA. 2001;285(19):2486-97.

22. Bruno G, Merletti F, Biggeri A, Bargero G, Ferrero S, Runzo C, et 


\section{Jalalzadeh $\mathrm{M}$ et al.}

al. Metabolic syndrome as a predictor of all-cause and cardiovascular mortality in type 2 diabetes: the Casale Monferrato Study. Diabetes Care. 2004;27(11):2689-94.

23. Shinohara K, Shoji T, Emoto M, Tahara H, Koyama H, Ishimura E, et al. Insulin resistance as an independent predictor of cardiovascular mortality in patients with end-stage renal disease. J Am Soc Nephrol. 2002;13(7):1894-900.

24. Kalantar-Zadeh K, Block G, Humphreys MH, Kopple JD. Reverse epidemiology of cardiovascular risk factors in maintenance dialysis patients. Kidney Int. 2003;63(3):793-808.

25. Hamada MA. Obesity and metabolic syndrome in Saudi hemodialysis patients. J Nephro Ren Transpl. 2009;2(3):18-27.

26. Garg A. Acquired and inherited lipodystrophies. $N$ Engl J Med. 2004;350(12):1220-34.

27. Stolic R, Trajkovic G, Peric V, Jovanovic A, Stolic D, Sovtic S, et al. [Frequency and characteristics of metabolic disorders in pa- tients on haemodialysis]. Vojnosanit Pregl. 2008;65(3):205-9.

28. Jalalzadeh M, Mohammadi R, Mirzamohammadi F, Ghadiani $\mathrm{MH}$. Prevalence of metabolic syndrome in a hemodialysis population. Iran J Kidney Dis. 2011;5(4):248-54.

29. Bakker SJ, Gansevoort RT, de Zeeuw D. Metabolic syndrome: a fata morgana? Nephrol Dial Transplant. 2007;22(1):15-20.

30. Johnson DW, Armstrong K, Campbell SB, Mudge DW, Hawley $\mathrm{CM}$, Coombes JS, et al. Metabolic syndrome in severe chronic kidney disease: Prevalence, predictors, prognostic significance and effects of risk factor modification. Nephrology (Carlton). 2007;12(4):391-8.

31. Bonora E, Targher G, Formentini G, Calcaterra F, Lombardi S, Marini F, et al. The Metabolic Syndrome is an independent predictor of cardiovascular disease in Type 2 diabetic subjects. Prospective data from the Verona Diabetes Complications Study. Diabet Med. 2004;21(1):52-8. 